\title{
Obstrucción maligna de la vía aérea central
}

\section{Malignant obstruction of the central airway}

LILIANA FERNÁNDEZ T, MD ${ }^{1}$

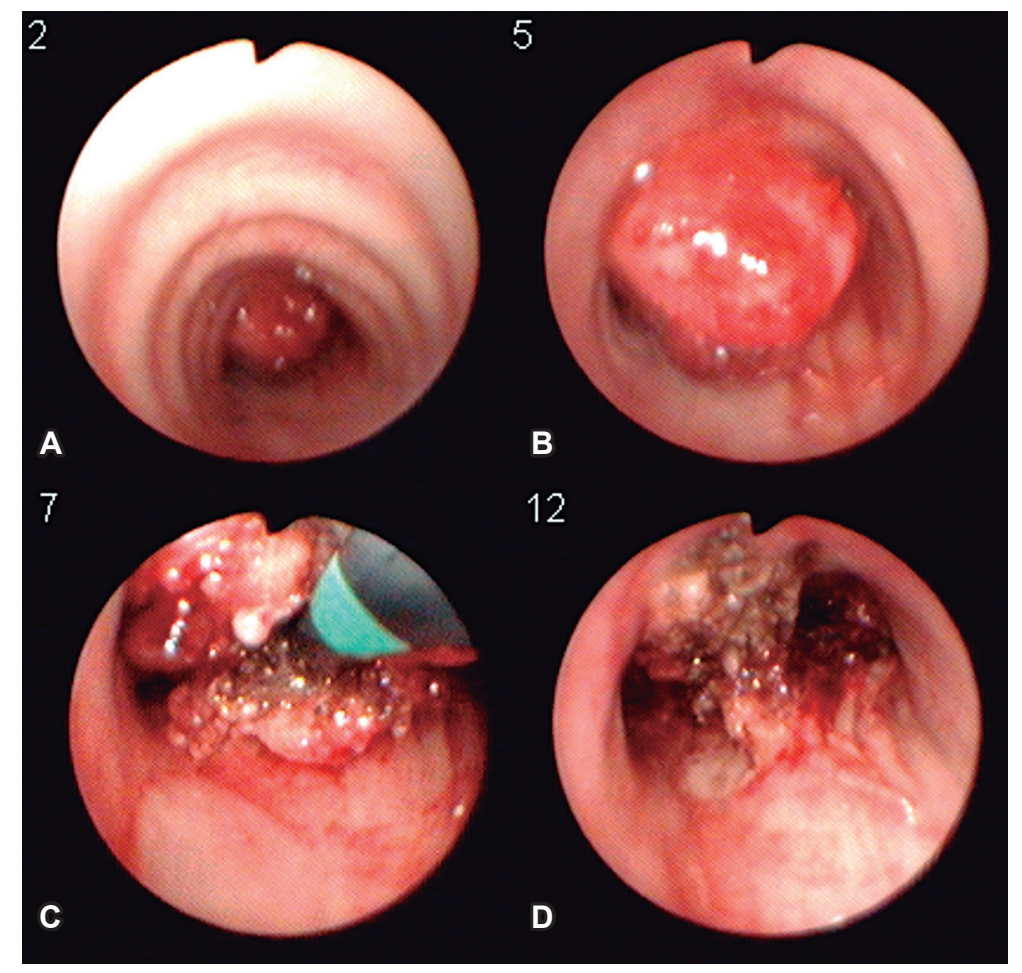

Figura 1. A y B. Adenocarcinoma en tercio inferior de la tráquea. C. Permeabilización con electrocauterio. D. Aspecto de la carina y los bronquios fuentes permeables.

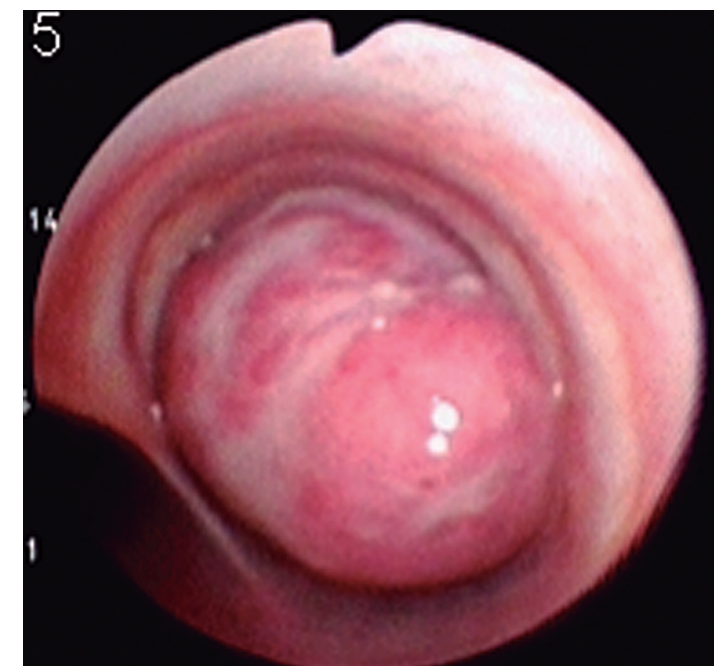

Figura 2. Tumor carcinoide típico de aspecto liso y brillante, muy vascularizado en bronquio fuente izquierdo.
Medicina Interna, Neumología, Neumología Intervencionista. Línea de investigación biomédica en tórax, Fundación Valle del Lili. Facultad de Ciencias de la Salud de la Universidad Icesi. Cali, Colombia.

Autor de correspondencia

Liliana Fernández T. Fundación Valle del Lili. Carrera 98 \#18-49; torre 2, piso 4, consultorio 446. Cali, Colombia. Tel.: $+57-331.90 .90$

Correos electrónicos: lilianafernandeztrujillo@gmail.com, liliana.fernandez@ fvl.org.co

Recibido: 15/11/17. Aceptado: 13/12/17. 


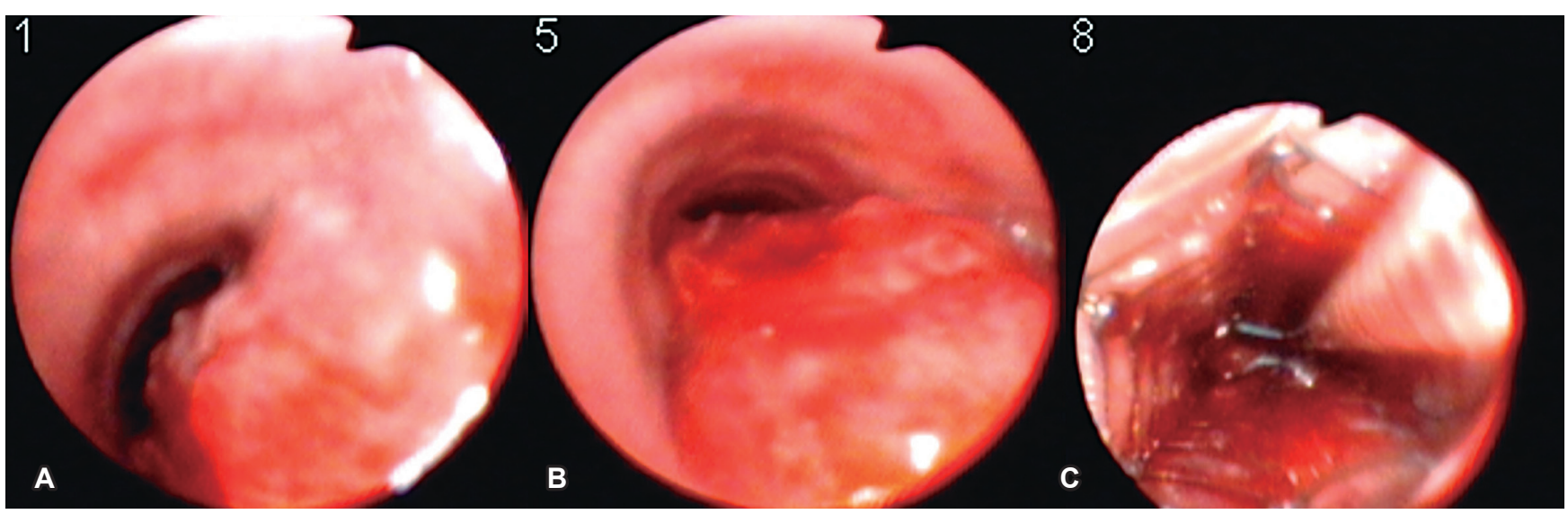

Figura 3. A, B y C. Tumor mediastinal que infiltra la tráquea en su tercio medio e inferior; además, causa compresión extrínseca que se somete a resección con electrocauterio y posterior colocación de stent metálico para paliación efectiva de la vía aérea.

La obstrucción de la vía aérea es una situación poco común, pero potencialmente fatal, caracterizada por la obstrucción de la tráquea y grandes bronquios por lesiones malignas y no malignas. La causa más común es el cáncer de pulmón. Este se presenta en $20 \%$ a $30 \%$ de los casos en algún momento de su evolución. Los síntomas, como tos y disnea, pueden ser insidiosos y lentamente progresivos hasta evolucionar a falla (o insuficiencia) respiratoria con inminencia de muerte si no hay una intervención oportuna. La terapia se encamina a restaurar y asegurar la vía aérea. La técnica elegida

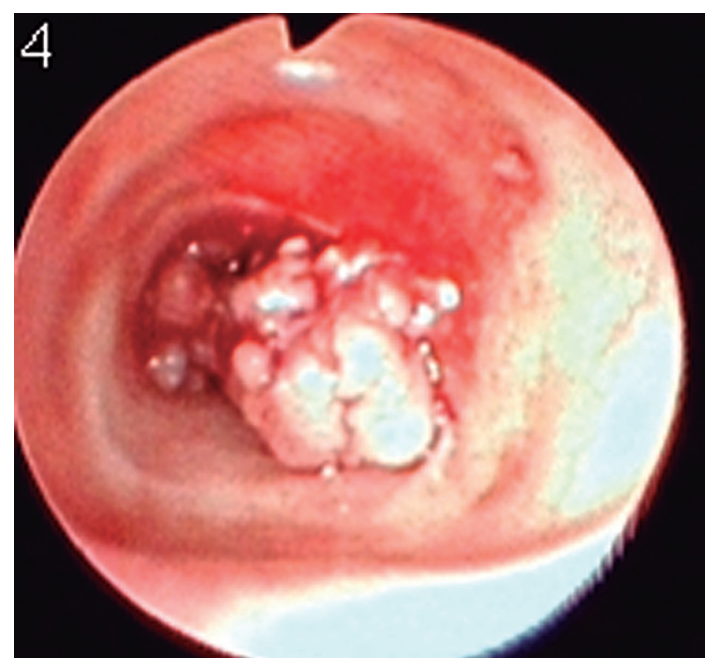

Figura 4. Tumor escamocelular primario de tráquea ubicado en la tráquea distal con obstrucción del $90 \%$. depende de la causa, tipo y severidad de la obstrucción, así como de la disponibilidad de equipos, habilidad del operador y del grupo multidisciplinario que se enfrente a cada caso. Actualmente se emplea terapia multimodal en el abordaje de estos pacientes. Esta involucra broncoscopia rígida y flexible bajo anestesia general o sedación profunda, utilizando equipos de ablación y resección, como láser, electrocauterio, sondas de crioterapia y de desbridamiento, argón plasma, prótesis, entre otros instrumentos diseñados para garantizar la estabilidad de la vía aérea $(1,2)$.

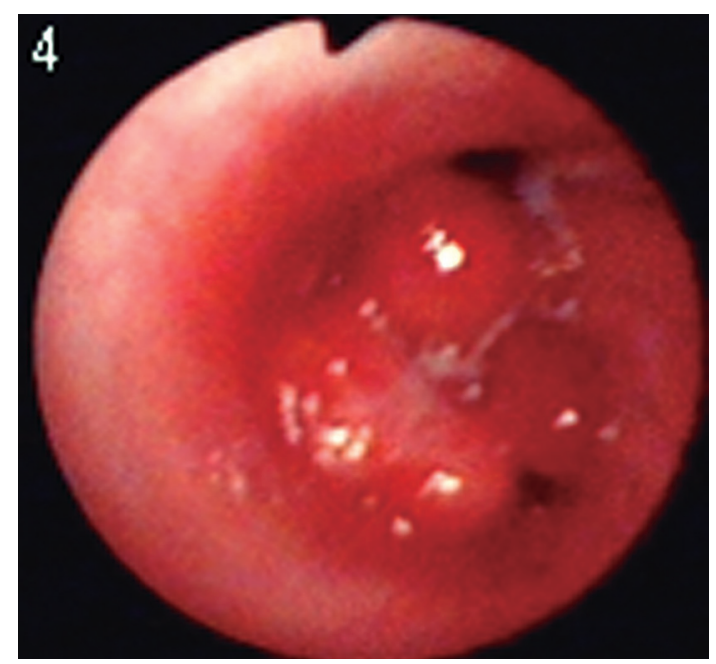

Figura 5. Carcinoide bronquial atípico, que causa obstrucción completa de bronquio fuente derecho. 


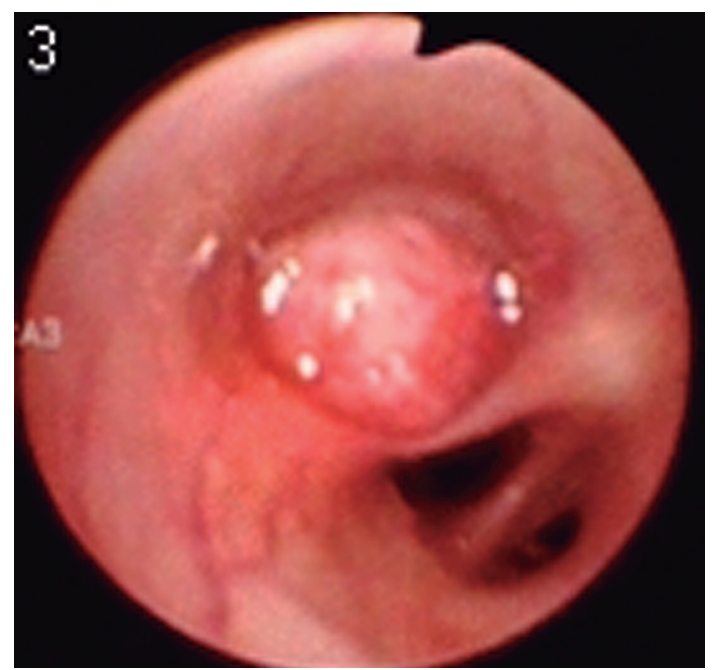

Figura 6. Sarcoma en pulmón derecho, lóbulo medio.

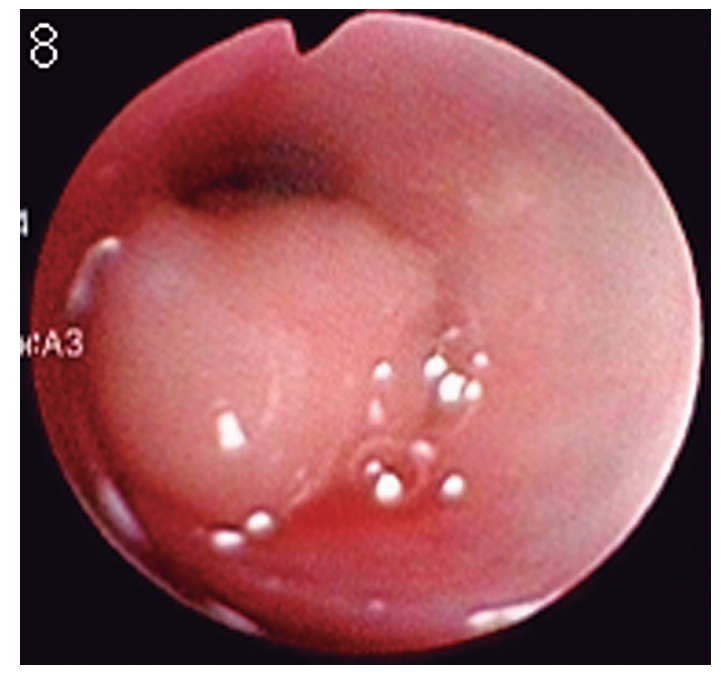

Figura 7. Adenocarcinoma EGFR (+) en una mujer no fumadora. Se ubica en el bronquio fuente izquierdo.

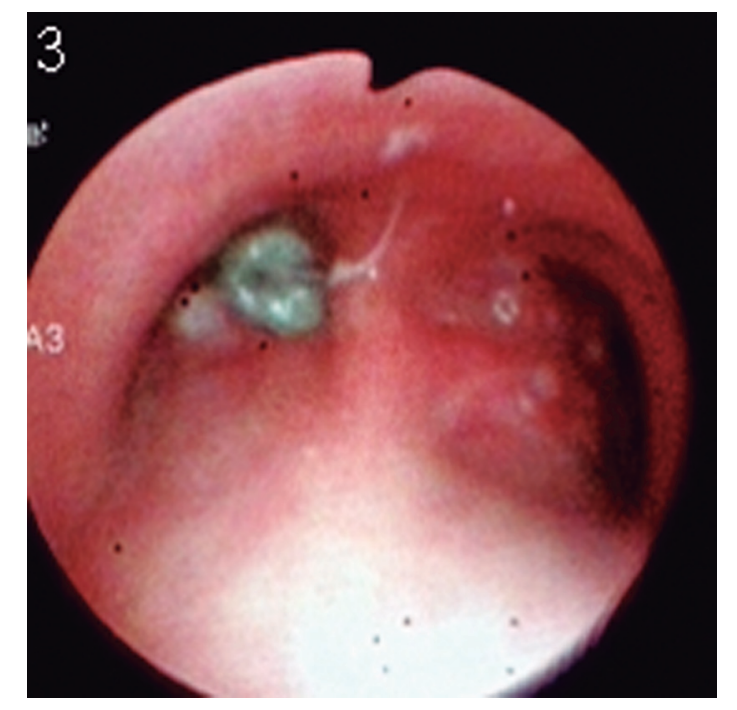

Figura 8. Compromiso de ambos bronquios fuentes por adenocarcinoma primario de pulmón ALK $\left(^{*}\right)$.

\section{Referencias}

1. Mahmood K, Wahidi MM. Ablative therapies for central airway obstruction. Semin Respir Crit Care Med. 2014;35(6):681-92. DOI: $10.1055 / \mathrm{s}-0034-1395501$.
2. Walters DM, Wood DE. Operative endoscopy of the airway. J Thorac Dis. 2016;8(2):S130-9. DOI: 10.3978/j.issn.20721439.2016.01.72. 